Check for updates

Cite this: RSC Adv., 2018, 8, 9006

Received 7th January 2018

Accepted 15th February 2018

DOI: $10.1039 / c 8 r a 00166 a$

rsc.li/rsc-advances

\section{Performance of a zeolite modified with $N, N-$ dimethyl dehydroabietylamine oxide (DAAO) for adsorption of humic acid assessed in batch and fixed bed columns $\dagger$}

\author{
Shaogang Liu, ${ }^{a}$ Wenzhen Zhang, ${ }^{a}$ Xuecai Tan, ${ }^{a}$ Fang Zhao, ${ }^{a}$ Wanting Huang, ${ }^{a}$ \\ Hanchun Du, ${ }^{b}$ Bernard A. Goodman, ${ }^{c}$ Fuhou Lei ${ }^{a}$ and Kaisheng Diao (D) *a
}

\begin{abstract}
Factors that affect adsorption of a synthetic humic acid (HA) on a zeolite modified with the surfactant $N, N$ dimethyl dehydroabietylamine oxide (DAAO) (SMZ) were investigated in batch and fixed bed column experiments. Adsorption increased with increasing HA concentrations and contact time, but decreased with increasing $\mathrm{pH}$, temperature, and ionic strength. Adsorption of $\mathrm{HA}$ on $\mathrm{SMZ}$ was increased by the presence of the cations $\mathrm{Ca}^{2+}$ and $\mathrm{Mg}^{2+}$, whereas anions such as $\mathrm{NO}_{3}{ }^{-}, \mathrm{HCO}_{3}{ }^{-}, \mathrm{SO}_{4}{ }^{2-}$, and $\mathrm{PO}_{4}{ }^{3-}$ showed the opposite trend, and competed with $\mathrm{HA}$ adsorption. HA adsorption on SMZ was well-fitted by pseudo-second order kinetics, and described by the Langmuir isotherm model. The maximum adsorption capacity in batch experiments calculated from the Langmuir adsorption isotherm was about $126 \mathrm{mg} \mathrm{g}^{-1}$. Thermodynamic calculations showed that HA adsorption on the zeolite with bilayer DAAO coverage was spontaneous and exothermic. Optimum desorption was obtained using $0.1 \mathrm{M} \mathrm{NaOH}$ with a recovery of $94 \%$. The HA adsorption capacity of SMZ at the breakthrough point was greatly influenced by bed depth, and could be described by the Thomas model. Adsorption mechanisms are interpreted as involving mainly hydrogen bonding and electrostatic interactions.
\end{abstract}

\section{Introduction}

Humic acid (HA) is an ubiquitous component of ground waters and drinking water sources. However, its presence in water can produce undesirable color and taste, and increase the contents of various pollutants by binding both heavy metals and organic chemicals (e.g., pesticides). More seriously, HA may react with disinfectants (e.g., free chlorine, monochloramine, and $\mathrm{ClO}_{2}$ ) during chlorination treatment of drinking water to form carcinogenic disinfection byproducts (DBPs), such as trihalomethanes, haloacetic acids, and haloacetonitriles. ${ }^{1}$ Therefore, efficient removal of HA from drinking water supplies or wastewaters is of great importance.

In recent years, various methods have been developed to remove HA from drinking water. These include coagulation/

\footnotetext{
${ }^{a}$ Guangxi Key Laboratory of Chemistry and Engineering of Forest Products, Guangxi Colleges and Universities Key Laboratory of Food Safety and Pharmaceutical Analytical Chemistry, School of Chemistry and Chemical Engineering, Guangxi University for Nationalities, Nanning 530008, Guangxi, China. E-mail: Diaokaisheng2010@163.com; Fax: +86771 3261079; Tel: +867713265310

${ }^{b}$ Guangxi Center for Analysis and Test Research, Nanning 530022, China

${ }^{c}$ College of Physical Science and Engineering, Guangxi University, Nanning 530004, Guangxi, China
}

$\dagger$ Electronic supplementary information (ESI) available. See DOI: 10.1039/c8ra00166a flocculation, membrane separation, biodegradation, adsorption, ion exchange, and chemical oxidation; among these, adsorption has advantages of low cost, ease of operation, and high efficiency. Various adsorbents have been investigated for the adsorption of HA from water and wastewater, including activated carbon, ${ }^{2}$ resins, ${ }^{3}$ layered clay minerals, ${ }^{4}$ zeolite,${ }^{5}$ and chitosan, ${ }^{6}$ but there is still great interest in the development of new more efficient adsorbents.

Zeolites (NZ) are three dimensional aluminosilicate minerals with porous structures, and cationic surfactant-modified NZ have been investigated extensively for the separation and removal of various pollutants from aquatic solutions, including dyes, humic substances, ${ }^{5,7}$ pesticides, ${ }^{8}$ and heavy metals. ${ }^{9}$ Commonly used surfactants for zeolite modification include tetramethylammonium, ${ }^{\mathbf{1 0}}$ hexadecyltrimethylammonium (HDTMA), ${ }^{11,12}$ octadecyldimethylbenzyl (ODMBA), ${ }^{13,14}$ and cetylpyridinium bromide. ${ }^{5}$ However, these surfactants are synthetic long-chain molecules with limited biodegradability, and on disposal can result in potentially negative impacts on the environment., ${ }^{5-17}$ Thus environmentally-friendly biodegradable surfactants are now attracting more attention.

Rosin obtained from conifer trees is a widely available environmentally friendly material, and consists mainly of resin acids, which are a widely available source of abietic acid. ${ }^{\mathbf{1 8 , 1 9}}$ Recently, we reported the synthesis of $N, N$-dimethyl 
dehydroabietylamine oxide (DAAO) and showed that it could modify a zeolite to efficiently remove a dye from aqueous solutions. ${ }^{20}$ The present work extends these investigations and reports the feasibility of using DAAO-modified zeolites as adsorbents to remove HA from water in batch and fixed bed columns. It considers the effects of various parameters on HA adsorption, including DAAO content, adsorbent dosage, $\mathrm{pH}$, ionic strength, co-existing ions, contact time, and temperature in batch adsorption experiments, and the effects of bed height on HA adsorption and the development of breakthrough curves in fixed column experiments. The experimental data were analyzed by kinetic and isotherm models, and thermodynamic parameters, such as Gibbs free energy change $\left(\Delta G_{\text {ads }}^{\text {o }}\right)$, heat of adsorption $\left(\Delta H_{\text {ads }}^{\mathrm{o}}\right)$, and entropy change $\left(\Delta S_{\text {ads }}^{\mathrm{o}}\right)$ of adsorption were calculated. Possible mechanisms are tentatively proposed for HA adsorption on the DAAO-modified zeolite.

\section{Materials and methods}

\subsection{Materials and reagents}

Natural zeolite (NZ) was from the Jinyun County, Zhejiang, China; it had a chemical composition of $\mathrm{SiO}_{2} 74.07 \%, \mathrm{Al}_{2} \mathrm{O}_{3}$ 15.60\%, $\mathrm{CaO} 3.16 \%, \mathrm{~K}_{2} \mathrm{O} 2.59 \%, \mathrm{Na}_{2} \mathrm{O} 1.91 \%, \mathrm{Fe}_{2} \mathrm{O}_{3} 1.34 \%$, $\mathrm{P}_{2} \mathrm{O}_{5} 0.43 \%, \mathrm{MgO} 0.41 \%, \mathrm{TiO}_{2} 0.17 \%$, with a LOI of $8.04 \%$, and an external cation exchangeable capacity (ECEC) of $130 \mathrm{meq}$ $\mathrm{kg}^{-1}$ determined using methylene blue method. ${ }^{21,22}$ Synthetic HA was purchased from Sigma-Aldrich Company (St. Louis, MO, USA). DAAO (purity 93\%) was synthesized as described in our previous work, ${ }^{23}$ and its physicochemical properties are listed in Table 1. Other chemicals were of the highest purity available, and all solutions were prepared with ultrapure water produced by a Milli-Q system (Advantage A10, Millipore, Billerica, MA, USA).

\subsection{Preparation and characterization of the adsorbent}

Modified zeolites were prepared by dissolving calculated amounts of DAAO at $60{ }^{\circ} \mathrm{C}$ in $250 \mathrm{~mL}$ of a water ethanol mixture $(50: 10, \mathrm{v} / \mathrm{v})$ acidified to $\mathrm{pH} 3.0$ with $\mathrm{HCl}$. DAAOmodified zeolites were prepared as described previously. ${ }^{20}$ In brief, the DAAO stock solution of a $50 \mathrm{mmol} \mathrm{L}^{-1}$ concentration was prepared prior to use in natural zeolite modification. A series of $10 \mathrm{~g}$ natural zeolites mixed with different volumes of DAAO solution ranging from 20, 30, 40, 50, 60, 72, and $80 \mathrm{~mL}$, which were named SMZ1, SMZ2, SMZ3, SMZ4, SMZ5, SMZ6 and SMZ7, respectively. The adsorbents were characterized by XRD, FE-SEM and FT-IR spectroscopy before and after adsorption of HA at $\mathrm{pH}$ 6.0. XRD patterns were obtained using a Bruker D8 ADVANCE X-ray diffractometer with $\mathrm{Cu}$ K $\alpha$ radiation (Siemens D5000 diffractometer, Bruker AXS Inc, Germany), operating at $40 \mathrm{kV}$ and $40 \mathrm{~mA}$. The surface morphologies of solid samples were examined using a JSM7500F FE-SEM (JEOL Ltd., Japan). Infrared spectra were recorded in $\mathrm{KBr}$ pellets on a Nicolet 5700 model FTIR spectrometer (Thermo Nicolet Corporation, USA). Zeta potentials of HA and SMZ were measured using a Zeta sizer 2000 Analyzer (Malvern, Mastersizer 2000 Instruments Co., USA) at an ionic strength of $1 \mathrm{mM} \mathrm{NaCl}$ and initial $\mathrm{pH}$ ranging from 3.0 to 11.0.

\subsection{Batch adsorption experiments}

The effects of DAAO load, adsorbent dosage, $\mathrm{pH}$, ionic strength, contact time, and temperature were investigated in batch experiments. Solutions were adjusted to the desired $\mathrm{pH}$ by addition of $0.1 \mathrm{~mol} \mathrm{~L}^{-1} \mathrm{HCl}$ or $\mathrm{NaOH}$ before the adsorbate. Kinetic studies were carried out at $20{ }^{\circ} \mathrm{C}$ for initial HA concentrations in the range $20-100 \mathrm{mg} \mathrm{L}^{-1}$. After predetermined time intervals, aliquots $(5.0 \mathrm{~mL})$ were withdrawn and centrifuged immediately at $5000 \mathrm{rpm}$ for $5 \mathrm{~min}$ to yield clear supernatant solutions.

All other adsorption experiments were carried out for $24 \mathrm{~h}$ to ensure equilibrium. Adsorption isotherms studies were conducted by varying initial HA concentrations from 10 to $100 \mathrm{mg} \mathrm{L}^{-1}$, by adding a constant amount of adsorbent $(0.05 \mathrm{~g})$ at $\mathrm{pH}$ 6.0, and then shaking the mixtures at $150 \mathrm{rpm}$ at the specified temperatures. The concentrations of HA remaining in solution were determined by absorption at $254 \mathrm{~nm}$ on a UV-Vis spectrometer (GBC Scientific Equipment, Australia). The adsorption amounts and removal efficiency of HA (\%) were calculated as follows:

$$
\begin{gathered}
\qquad q_{t}=\frac{\left(C_{0}-C_{t}\right) V}{m} \\
\text { HA removal efficiency } \%=\frac{\left(C_{0}-C_{t}\right)}{C_{0}} \times 100
\end{gathered}
$$

where $C_{0}$ and $C_{t}\left(\mathrm{mg} \mathrm{L}^{-1}\right)$ are the initial concentrations of HA and at time $t$, respectively; $q_{t}\left(\mathrm{mg} \mathrm{g}^{-1}\right)$ is the amount of HA adsorbed at equilibrium; $V$ is the volume of HA solution $(\mathrm{L}) ; m$ is

\begin{tabular}{|c|c|c|c|c|}
\hline$\gamma_{\mathrm{cmc}}\left(\mathrm{mN} \mathrm{m}^{-1}\right)$ & Type & $\mathrm{MW}\left(\mathrm{g} \mathrm{mol}^{-1}\right)$ & Activity (\%) & Molecular structure \\
\hline $22-36$ & Amine oxide & 330 & 93 & \\
\hline
\end{tabular}

Table 1 Physicochemical properties of the DAAO used in this study 


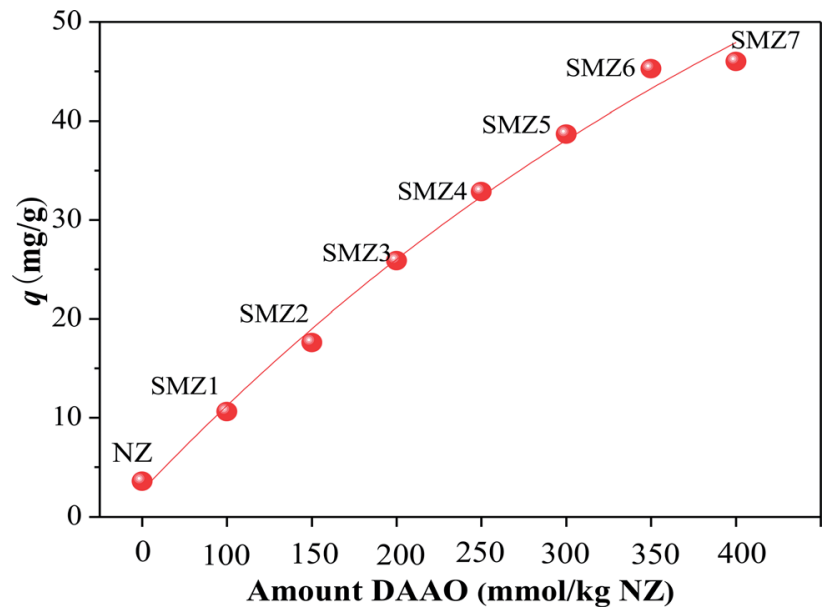

Fig. 1 Effect of DAAO loading on HA adsorption by SMZs. Experimental conditions: $[\mathrm{HA}]_{0}=40 \mathrm{mg} \mathrm{L}^{-1}$, [adsorbent dosage] $=1.0 \mathrm{~g} \mathrm{~L}^{-1}$, contact time $=24 \mathrm{~h}, \mathrm{pH}=6.0, T=20 \pm 1^{\circ} \mathrm{C}$.

the mass of adsorbent $(\mathrm{g})$. All adsorption experiments were performed in duplicate.

\subsection{Desorption and regeneration studies}

In order to better understand the mechanism of HA adsorption on SMZ, desorption measurements were performed in batch experiments with $50 \mathrm{mg} \mathrm{SMZ} \mathrm{treated} \mathrm{with} 50 \mathrm{~mL}$ HA solution (50 $\mathrm{mg} \mathrm{L}^{-1}, \mathrm{pH}$ 6.0) (derived from Section 2.4) using either $0.1 \mathrm{M}$ $\mathrm{NaOH}$ or $\mathrm{HCl}$ solutions as desorbing agent. The concentrations of HA desorbed from the adsorbents were determined by absorption at $254 \mathrm{~nm}$ as described above. The adsorptionregeneration cycles were repeated four times, and the efficiency of desorption of HA from the adsorbent was calculated by the following equation:

$$
\text { Desorption efficiency }(\%)=\frac{q_{\mathrm{de}}}{q_{\mathrm{ad}}} \times 100
$$

where $q_{\mathrm{de}}$ and $q_{\mathrm{ad}}$ are the HA concentrations $\left(\mathrm{mg} \mathrm{L}^{-1}\right)$ desorbed from SMZ and adsorbed at equilibrium, respectively.

\subsection{Fixed-bed column experiments}

The effect of bed depth on HA adsorption was studied in glass columns $(\varnothing 1.1 \mathrm{~cm} \times 50 \mathrm{~cm})$ packed to various depths $(10,20$ and $30 \mathrm{~cm}$ ) with SMZ (particle size $0.5-0.8 \mathrm{~mm}$ ). An initial concentration of $40 \mathrm{mg} \mathrm{L}^{-1} \mathrm{HA}(\mathrm{pH} 6.0)$ was passed through the column at a rate of approximately $4.0 \mathrm{~mL} \mathrm{~min}^{-1}$ and effluent solutions were analyzed for HA at various time intervals.

\section{Results and discussion}

\subsection{HA batch adsorption studies}

3.1.1 Effect of amount of DAAO loaded on SMZs on HA adsorption. The amounts of DAAO in SMZ1, SMZ2, SMZ3, SMZ4, SMZ5, SMZ6, and SMZ7 were found to be 90.9, 136.3, 181.5, 222.4, 255.9, 270.9, and $290.2 \mathrm{mmol} \mathrm{kg}^{-1}$ (NZ), respectively. ${ }^{20}$ Thus SMZ1 and SMZ2 had DAAO monolayers, SMZ3,

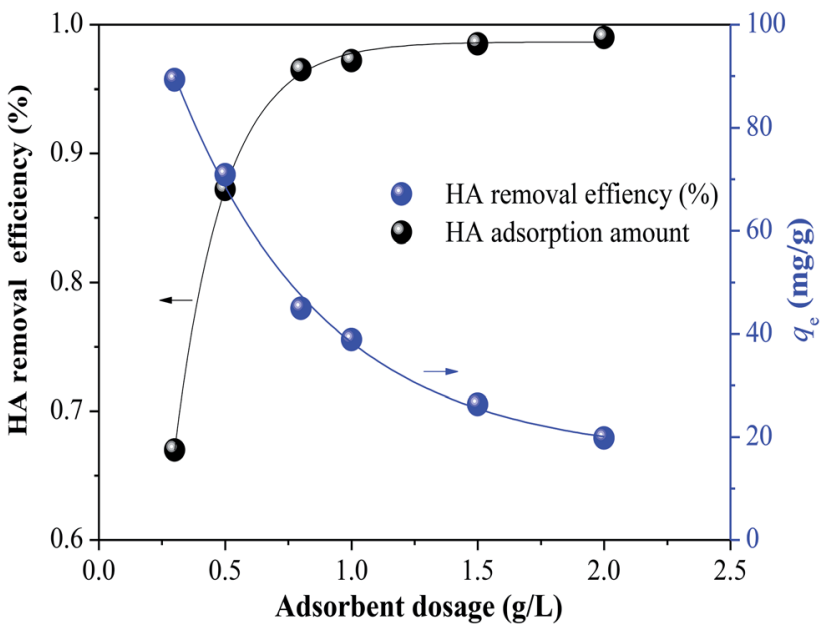

Fig. 2 Effect of dosage of SMZ6 adsorbent on HA adsorption. Experimental conditions: $[\mathrm{HA}]_{0}=40 \mathrm{mg} \mathrm{L}^{-1}$, contact time $=24 \mathrm{~h}, \mathrm{pH}$ $=6.0, T=20 \pm 1{ }^{\circ} \mathrm{C}$.

SMZ4 and SMZ5 had patchy bilayer coverage, and SMZ6 and SMZ7 had DAAO bilayer coverage. ${ }^{20}$ Results from elemental analyses also showed that DAAO was associated with the zeolite (Table S1†).

The amounts of HA adsorbed on SMZs loaded with different amounts of DAAO are shown in Fig. 1. The original NZ had little affinity for HA, but the HA adsorption efficiency on the SMZs increased with increasing DAAO loading, although there was only a small difference between SMZ6 and SMZ7. Thus maximum adsorption corresponds to complete bilayer DAAO coverage, and SMZ6 was used as the adsorbent in subsequent experiments.

3.1.2 Effect of adsorbent dosage. The effect of adsorbent dosage on HA adsorption by SMZ6 is shown in Fig. 2. There was a major increase in HA adsorption for dosages in the range 0.3 to $0.8 \mathrm{~g} \mathrm{~L}^{-1}$, but only small increases in the range 1.0 to $2.0 \mathrm{~g}$ $\mathrm{L}^{-1}$. Considering efficiency and economy, $0.8 \mathrm{~g} \mathrm{~L}^{-1}$ was chosen as the optimum adsorbent dosage for the following experiments to assess the effects of other factors on the adsorption efficiency.

\subsection{Effect of $\mathbf{p H}$}

Solution $\mathrm{pH}$ is an important parameter that affects the adsorption process. Its effect on HA adsorption by SMZ6 is shown in Fig. 3a, together with the zeta potentials of HA and SMZ6 in the pH range 3.0-11.0. The amount of HA adsorbed by SMZ6 decreased monotonously from $49.4 \mathrm{mg} \mathrm{g}^{-1}(98.8 \%$ removal efficiency) to $7.3 \mathrm{mg} \mathrm{g}^{-1}$ (14.7\% removal efficiency) as the $\mathrm{pH}$ was increased from 3.0 to 11.0. Generally, the $\mathrm{pH}$ influences the surface charge, degree of ionization and speciation of both the HA and DAAO, and this result is consistent with the behavior of humic substances associated with soils where they are separated by dissolution in alkali and precipitation with acid. As seen in Fig. 3b, the zeta potential of both SMZ6 and HA decreased progressively with increasing $\mathrm{pH}$. However, SMZ6 has a positively charged surface at low $\mathrm{pH}$, but 

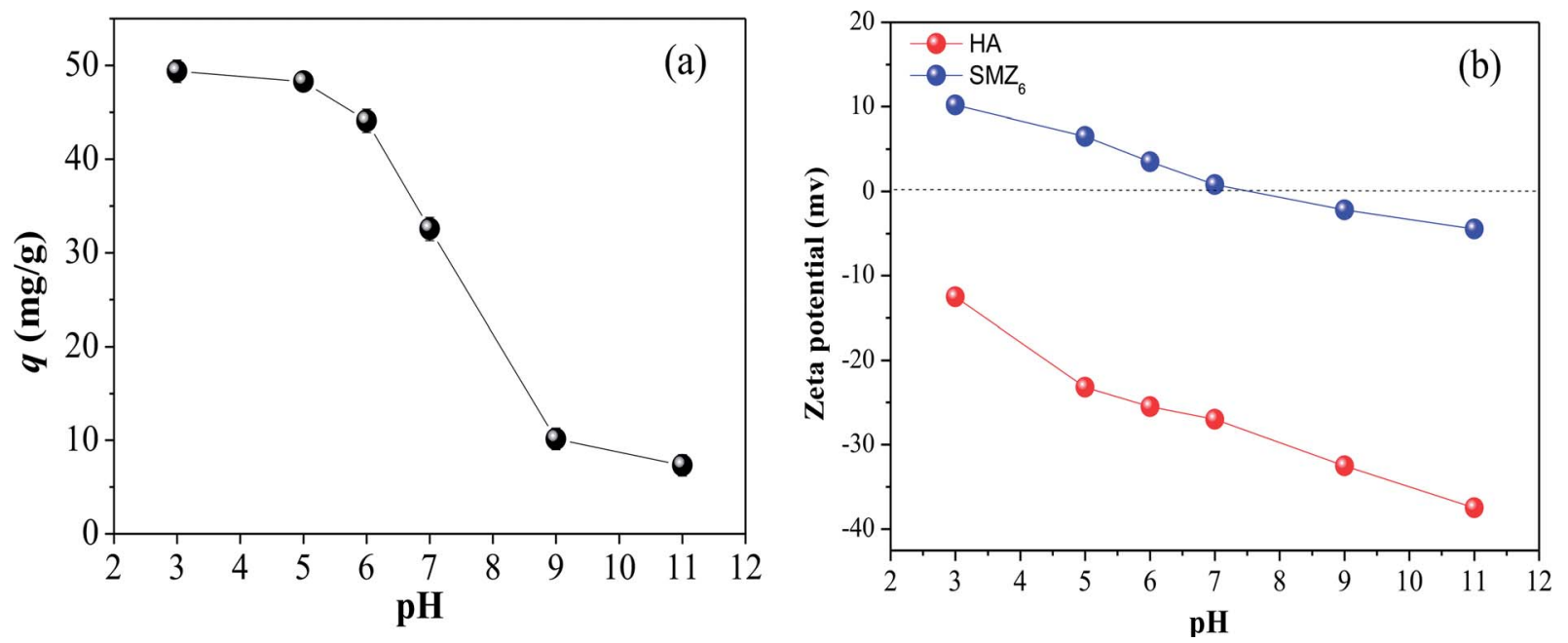

Fig. 3 (a) Effect of $\mathrm{pH}$ on HA adsorption on SMZ6, and (b) zeta potentials of $\mathrm{HA}$ and SMZ6. Experimental conditions: $[\mathrm{HA}]_{0}=40 \mathrm{mg} \mathrm{L}^{-1}$, SMZ6 $=$ $0.8 \mathrm{~g} \mathrm{~L}^{-1}$, contact time $=24 \mathrm{~h}, \mathrm{pH}=6.0, T=20 \pm 1^{\circ} \mathrm{C}$.

a negatively charged surface at high $\mathrm{pH}$ with the $\mathrm{pH}_{\mathrm{PZC}}$ at 7.4, whereas HA molecules have negative charges over the entire tested $\mathrm{pH}$ range, and their low isoelectric point $(\text { IEP }=1.9)^{24}$ results in deprotonation of carboxyl groups. In the lower $\mathrm{pH}$ range $\left(\mathrm{pH}<\mathrm{pH}_{\mathrm{ZPC}}\right)$, protonation of DAAO produces a positive charge center on SMZ (i.e. $\mathrm{R}-\mathrm{N}\left(\mathrm{CH}_{3}\right)_{2} \rightarrow \mathrm{O}+\mathrm{H}^{+} \leftrightarrow \mathrm{R}-\mathrm{N}^{+}\left(\mathrm{CH}_{3}\right)_{2}$ $\rightarrow \mathrm{OH}, \mathrm{R}=$ dehydroabietyl base), resulting in a strong electrostatic attraction to the $\mathrm{RCOO}^{-}$groups of $\mathrm{HA}$, and high adsorption of HA on the modified zeolite. In addition, hydrogen bonding may also occur, because DAAO can act as both a hydrogen bonding donor and receptor. ${ }^{20}$ However, when the $\mathrm{pH}$ was increased in the range 7 to $11, \mathrm{HA}$ adsorption decreased sharply, because deprotonation of DAAO results in a loss of electrostatic attraction, and HA adsorption is dependent on hydrogen bonding, and possibly other mechanisms, such as hydrophobic interactions. These conclusions are, therefore, consistent with results reported for HA adsorption on activated

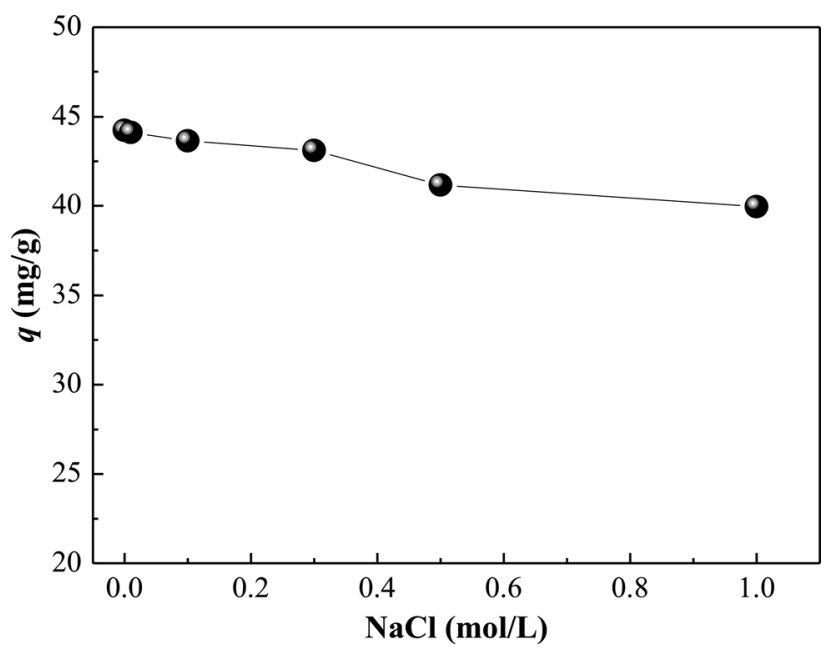

Fig. 4 Effect of ionic strength on HA adsorption on SMZ6. Experimental conditions: $[\mathrm{HA}]_{0}=40 \mathrm{mg} \mathrm{L}^{-1}, \mathrm{SMZ} 6=0.8 \mathrm{~g} \mathrm{~L}^{-1}$, contact time $=24 \mathrm{~h}, \mathrm{pH}=6.0, T=20 \pm 1{ }^{\circ} \mathrm{C}$. carbon, chitosan hydrobeads, and HTAMB modified attapulgite. ${ }^{2,6}$

\subsection{Effect of ionic strength}

The effect of ionic strength on the adsorption of HA on SMZ6 was studied with various concentrations of $\mathrm{NaCl}$. Adsorption decreased linearly with $\mathrm{NaCl}$ concentration up to $1.0 \mathrm{M}$ the highest concentration tested (Fig. 4). This result supports the anion exchange mechanism for HA adsorption, because the increasing presence of $\mathrm{Cl}^{-}$at higher ionic strengths increases competition with HA for the adsorption sites.

\subsection{Effect of coexisting ions}

Previous studies suggested that oxyanions (e.g., $\mathrm{SO}_{4}{ }^{2-}, \mathrm{NO}_{3}{ }^{-}$, $\mathrm{HCO}_{3}{ }^{-}$, and $\mathrm{PO}_{4}{ }^{3-}$ ) and divalent cations (e.g., $\mathrm{Ca}^{2+}$ and $\mathrm{Mg}^{2+}$ )

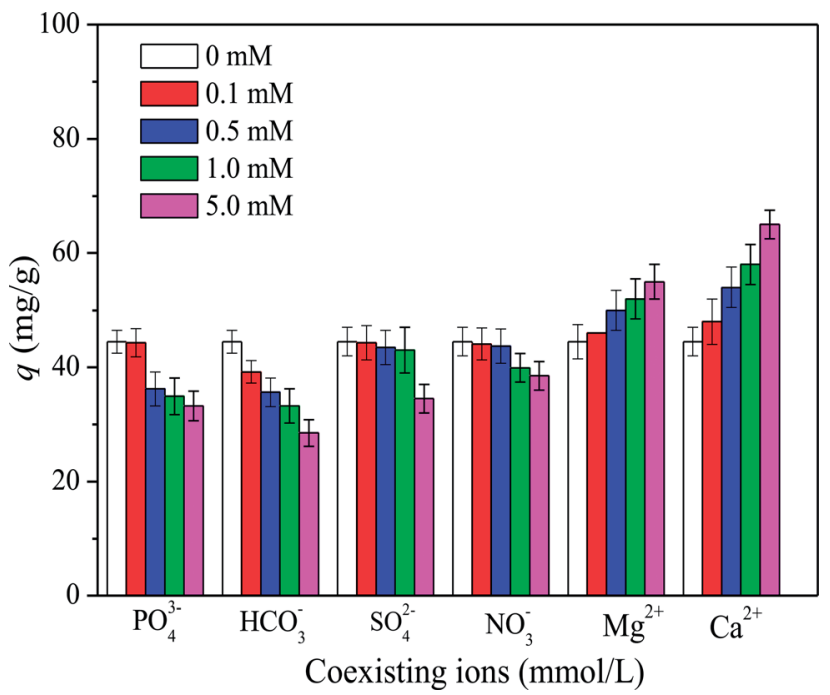

Fig. 5 Effect of co-existing ions on HA adsorption on SMZ6. Experimental conditions: $[\mathrm{HA}]_{0}=40 \mathrm{mg} \mathrm{L}^{-1}, \mathrm{SMZ6}=0.8 \mathrm{~g} \mathrm{~L}^{-1}$, contact time $=24 \mathrm{~h}, \mathrm{pH}=6.0, T=20 \pm 1^{\circ} \mathrm{C}$. 


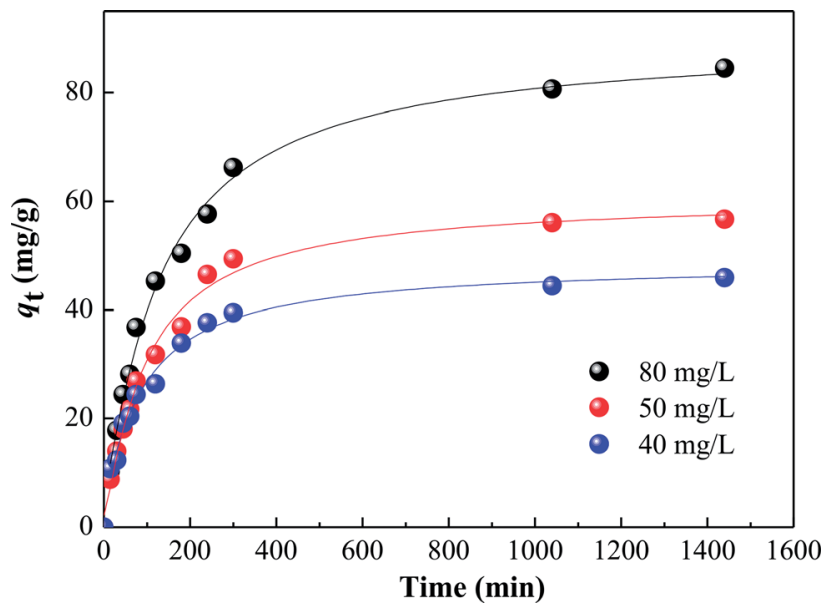

Fig. 6 Kinetics of HA adsorption on SMZ6 at various initial HA concentrations. Experimental conditions: $\mathrm{SMZ6}=0.8 \mathrm{~g} \mathrm{~L}^{-1}, \mathrm{pH}=6.0$, $T=20 \pm 1{ }^{\circ} \mathrm{C}$.

could significantly influence the adsorption of organic matter from natural waters. ${ }^{1}$ Fig. 5 shows that HA adsorption on SMZ6 decreased with increasing anion concentrations in the order $\mathrm{NO}_{3}{ }^{-}<\mathrm{SO}_{4}{ }^{2-}<\mathrm{HCO}_{3}{ }^{-}<\mathrm{PO}_{4}{ }^{3-}$. $\mathrm{HCO}_{3}{ }^{-}$and $\mathrm{PO}_{4}{ }^{3-}$ as Bronsted bases have a strong influence on the HA adsorption, and probably compete with HA for sorption sites on SMZ. Another reason may be attributed to the salting effect on HA adsorption. In contrast, $\mathrm{Ca}^{2+}$ and $\mathrm{Mg}^{2+}$ had a favorable effect on HA adsorption on SMZ6, probably because of their abilities to combine with anionic groups on both HA and SMZ particles and thereby increase electrostatic attraction as well as bonding directly with the HA and adsorbent. As a result, $\mathrm{Ca}^{2+}$ and $\mathrm{Mg}^{2+}$ can link the SMZ6 particle with HA, forming an SMZ6-metalHA complex that can significantly enhance adsorption. ${ }^{25,26}$ Furthermore, direct bonding of the divalent cation $\mathrm{Cu}^{2+}$ to both $\mathrm{HA}$ and the aluminosilicate mineral was observed by Goodman et al. ${ }^{27}$ in investigations of the adsorption of $\mathrm{Cu}-\mathrm{HA}$ complexes on montmorillonite and imogolite at $\mathrm{pH}$ 7. In that work, the $\mathrm{Cu}$ remained bound to the HA when adsorbed on montmorillonite, but was present mainly as the uncomplexed ion on imogolite.

\subsection{Adsorption kinetics}

The effects of contact time on HA adsorption at various initial HA concentrations (40-80 $\mathrm{mg} \mathrm{L}^{-1}$ ) are shown in Fig. 6. For each concentration, there was fast adsorption in the initial 60 minutes, which then slowed progressively, and became virtually constant after about 350 minutes. In order to further evaluate the adsorption mechanism, particularly the potential ratecontrolling step, four kinetic models, namely pseudo-firstorder, pseudo-second-order, ${ }^{28}$ and intra-particle diffusion ${ }^{29}$ were used to analyze the data in Fig. 6. From the linear forms of the first three of these models, equations can be written as follows:

First-order kinetic equation:

$$
\log \left(q_{\mathrm{e}}-q_{t}\right)=\log q_{\mathrm{e}}-\frac{k_{1}}{2.303} t
$$

Second-order kinetic equation:

$$
\frac{t}{q_{t}}=\frac{1}{k_{2} q_{\mathrm{e}}^{2}}+\frac{t}{q_{\mathrm{e}}}
$$

Intraparticle diffusion equation:

$$
q_{t}=k_{\mathrm{p}} t^{0.5}+C
$$

where $q_{t}$ and $q_{\mathrm{e}}$ are the amounts of HA adsorbed $\left(\mathrm{mg} \mathrm{g}^{-1}\right)$ at time $t$ and at equilibrium time, respectively; $k_{1}\left(\mathrm{~min}^{-1}\right)$ and $k_{2}(\mathrm{~g}$ $\mathrm{mg}^{-1} \mathrm{~min}^{-1}$ ) are rate constants, respectively. $t^{0.5}$ is the square root of the time and $k_{\mathrm{p}}\left(\mathrm{mg} \mathrm{g}^{-1} \min ^{0.5}\right)$ is the intra-particle diffusion rate constant. $C$ is the intercept, which represents the thickness of the boundary layer.

The various kinetic parameters derived from these models are listed in Table 2, which shows that the experimental data fit well to the second-order equation $\left(R^{2}>0.99\right)$, and the calculated $q_{\mathrm{e}}$ value is in good agreement with the experimental data. However, the intra-particle diffusion model does not fit the whole experimental adsorption data, which can be divided into two or three phases (Fig. 7), corresponding to external surface adsorption followed by internal surface adsorption. This result is consistent with previous findings. ${ }^{30}$

The adsorption of organic pollutants by porous adsorbents is controlled by external, interfacial, and internal diffusion. In Fig. 8, the kinetic data are also fitted to a simplified homogeneous surface diffusion model (HSDM) ${ }^{31}$

$$
\frac{q_{t}}{q_{\mathrm{e}}}=1-\frac{6}{\pi^{2}} \exp \left(\frac{-D_{\mathrm{s}} \pi^{2} t}{R^{2}}\right)
$$

where $D_{\mathrm{S}}$ is the intra-particle diffusion coefficient $\left(\mathrm{cm}^{2} \mathrm{~s}^{-1}\right)$, and

\begin{tabular}{|c|c|c|c|c|c|c|c|c|c|c|c|}
\hline 40 & 45.89 & 6.2 & 38.91 & 0.981 & 3.2 & 47.61 & 1.07 & 0.997 & 1.13 & 11.16 & 0.789 \\
\hline 50 & 58.66 & 6.4 & 53.23 & 0.986 & 2.5 & 61.72 & 1.83 & 0.999 & 1.507 & 12.5 & 0.815 \\
\hline 80 & 84.50 & 2.7 & 63.84 & 0.948 & 0.857 & 91.74 & 0.75 & 0.999 & 2.239 & 11.92 & 0.879 \\
\hline
\end{tabular}
$R$ is the average adsorbent particle radius. However, the $D_{\mathrm{s}}$ values in the range $6.59-8.81 \times 10^{-7} \mathrm{~cm}^{2} \mathrm{~s}^{-1}$ are larger than

Table 2 Kinetic parameters for the adsorption of HA onto SMZ6 


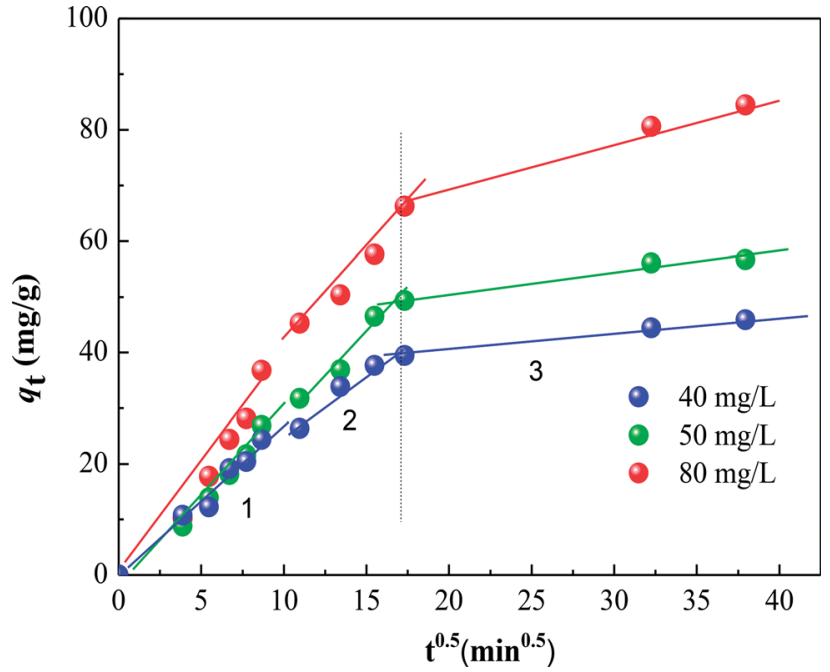

Fig. 7 Intra-particle diffusion model fits to the data for the adsorption of different initial HA concentrations on SMZ6.

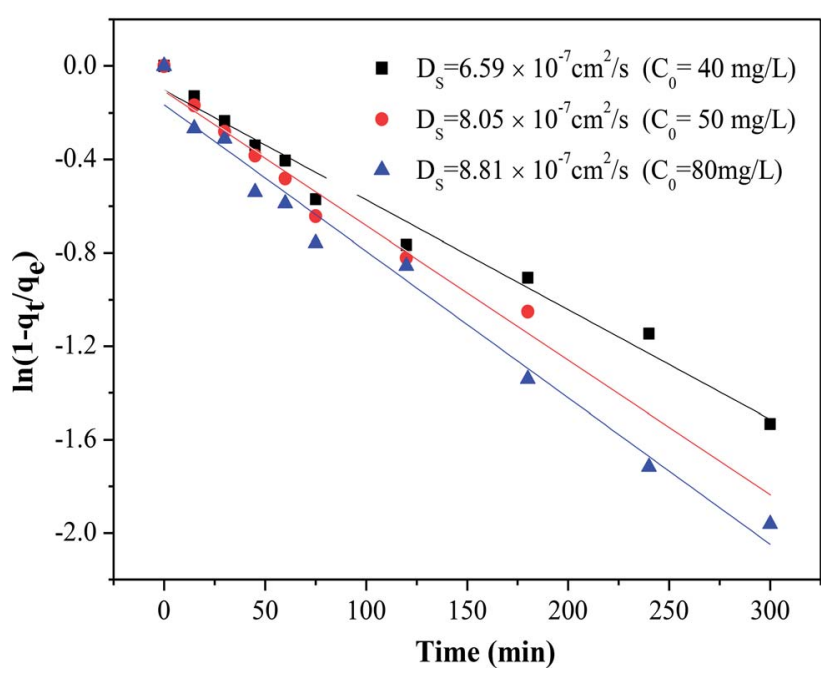

Fig. 8 Intra-particle diffusion model plot for the adsorption of HA on SMZ6.

those reported previously. ${ }^{32}$ Thus film diffusion may represent the rate-limiting process for HA adsorption on SMZ6. It is postulated that HA molecules are rapidly adsorbed on the external surface of the SMZ6, and that after saturation of the surface, they slowly penetrate the SMZ by intra-particle diffusion through pore and interior surface diffusion until equilibrium is attained. Consequently, the adsorption of HA from aqueous solution using SMZ is a complex process, involving both boundary layer and intra-particle diffusion.

\subsection{Adsorption isotherm and thermodynamics}

The adsorption isotherms for HA on SMZ6 at $20-40{ }^{\circ} \mathrm{C}$ are shown in Fig. 9. The amount of adsorbed HA decreased with increasing temperature, indicating that lower temperatures

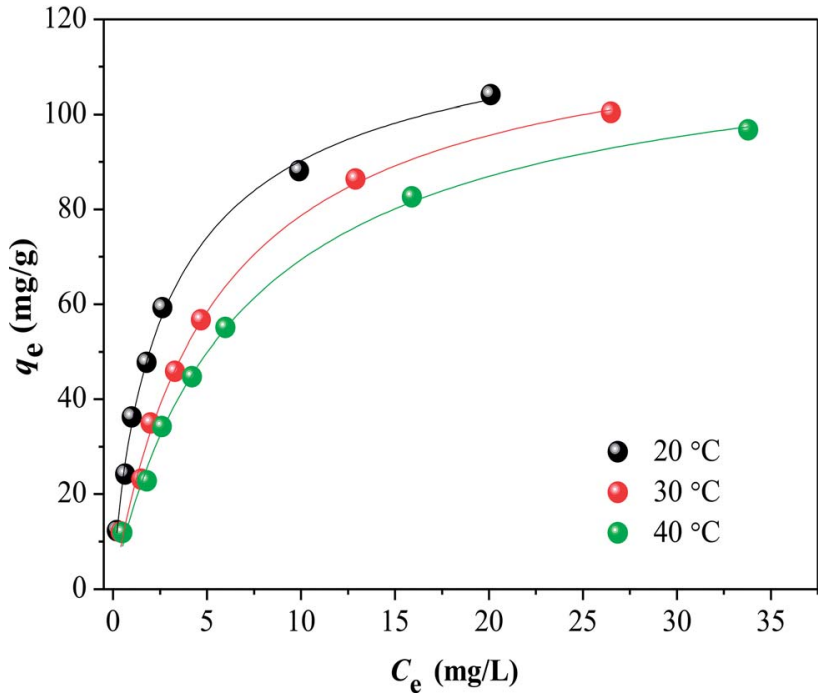

Fig. 9 Isotherms for adsorption of HA on SMZ6 at 20, 30, $40{ }^{\circ} \mathrm{C}$. Experimental conditions: $\mathrm{SMZ6}=0.8 \mathrm{~g} \mathrm{~L}^{-1}, \mathrm{pH}=6.0, \mathrm{~T}=20 \pm 1{ }^{\circ} \mathrm{C}$.

favor the adsorption process. To further understand the adsorption mechanism, the experimental data were analyzed by the Langmuir, Freundlich and Temkin adsorption isotherm models.

Langmuir model: ${ }^{33}$

$$
q_{\mathrm{e}}=\frac{q_{\mathrm{m}} K_{\mathrm{L}} C_{\mathrm{e}}}{1+K_{\mathrm{L}} C_{\mathrm{e}}}
$$

Freundlich model: ${ }^{34}$

$$
q_{\mathrm{e}}=K_{\mathrm{F}} C_{\mathrm{e}}^{1 / n}
$$

Temkin model: ${ }^{35}$

$$
q_{\mathrm{e}}=B \ln A_{\mathrm{T}}+B \ln C_{\mathrm{e}}
$$

where $K_{\mathrm{L}}$ and $q_{\mathrm{m}}$ are constants related to affinity of the binding sites $\left(\mathrm{L} \mathrm{mg}^{-1}\right)$ and adsorption capacity $\left(\mathrm{mg} \mathrm{g}^{-1}\right)$, respectively; $K_{\mathrm{F}}$ and $1 / n$ are the Freundlich constants related to surface heterogeneity of the adsorbent; $A$ and $B$ are the isotherm equilibrium binding constant $\left(\mathrm{L} \mathrm{g}^{-1}\right)$ and isotherm constants in the Temkin model.

The parameters calculated for these isotherms are listed in Table S2. $\dagger$ These show that the data are best fitted by the Langmuir model $\left(R^{2}=0.99\right)$, and thus HA is adsorbed as a monolayer. The theoretical capacities for HA adsorption on SMZ6 at 20, 30 and $40{ }^{\circ} \mathrm{C}$ are 126.6, 123.1 and $119.8 \mathrm{mg} \mathrm{g}^{-1}$, respectively, and are comparable to or greater than those that have been published for other adsorbents (Table 3).

The negative effect of increasing temperature on HA adsorption indicates that the adsorption process is exothermic. The thermodynamic parameters, Gibb's free energy $\left(\Delta G_{\mathrm{ads}}^{\mathrm{o}}\right)$, entropy $\left(\Delta S_{\mathrm{ads}}^{\mathrm{o}}\right)$ and enthalpy $\left(\Delta H_{\mathrm{ads}}^{\mathrm{o}}\right)$ changes for adsorption of HA onto SMZ6 were calculated using the following equations. ${ }^{42}$ 
Table 3 Thermodynamic parameters for adsorption of HA onto SMZ6

\begin{tabular}{|c|c|c|c|c|}
\hline Adsorbent & $q_{\mathrm{m}}\left(\mathrm{mg} \mathrm{g}^{-1}\right)$ & $T\left({ }^{\circ} \mathrm{C}\right)$ & $\mathrm{pH}$ & Reference \\
\hline Aminopropyl functionalized SBA-15 & 117.6 & 25 & 7.0 & 37 \\
\hline Cetylpyridinium bromide modified zeolite & 92.0 & 25 & 7.5 & 5 \\
\hline Chitosan treated granular activated carbon & 71.4 & 25 & 4.0 & 30 \\
\hline Crosslinked chitosan-epichlorohydrin beads & 44.84 & $27 \pm 1$ & 6.0 & 38 \\
\hline $\mathrm{Mg} / \mathrm{Fe}$ layered double hydroxide & 76.70 & $\mathrm{RT}$ & 7.0 & 41 \\
\hline Polyaniline/attapulgite composite & 61.35 & 25 & 5.0 & 24 \\
\hline SMZ6 & 126.6 & 20 & 5.0 & This study \\
\hline
\end{tabular}

$$
\begin{aligned}
& \Delta G_{\mathrm{ads}}^{\mathrm{o}}=-R T \ln K_{\mathrm{d}} \\
& \ln K_{\mathrm{d}}=\frac{\Delta S_{\mathrm{ads}}^{\mathrm{o}}}{R}-\frac{\Delta H_{\mathrm{ads}}^{\mathrm{o}}}{R T}
\end{aligned}
$$

where $K_{\mathrm{d}}$ is the adsorption distribution coefficient $\left(K_{\mathrm{d}}=C_{\mathrm{ad}} / C_{\mathrm{e}}\right)$, $C_{\mathrm{ad}}$ is the concentration of solute on the SMZ6 at equilibrium, and $R$ is the universal gas constant $\left(8.314 \mathrm{~J} \mathrm{~mol}^{-1} \mathrm{~K}^{-1}\right)$. The $\Delta H_{\text {ads }}^{\mathrm{o}}$ and $\Delta S_{\text {ads }}^{\mathrm{o}}$ parameters were calculated from the slope and intercept of a plot of $\ln K_{\mathrm{d}}$ versus $1 / T$ (Fig. S1†), and the calculated thermodynamic parameters are summarized in Table S3. $\dagger$

The negative values of $\Delta G_{\text {ads }}^{\mathrm{o}}\left(-5.52\right.$ to $\left.-6.95 \mathrm{~kJ} \mathrm{~mol}^{-1}\right)$ at all temperatures indicate the thermodynamic feasibility and spontaneous nature of the adsorption process. Generally, values of $\Delta G_{\text {ads }}^{\mathrm{o}}$ for physisorption are between -20 and $0 \mathrm{~kJ} \mathrm{~mol}^{-1}$, and for chemisorption between -400 and $-80 \mathrm{~kJ} \mathrm{~mol}^{-1}$. $^{43}$ The negative value of $\Delta H_{\mathrm{ads}}^{\mathrm{o}}\left(-27.93 \mathrm{~kJ} \mathrm{~mol}^{-1}\right)$ indicates that the adsorption of HA on SMZ6 is an exothermic process. The negative value for $\Delta S_{\text {ads }}^{\mathrm{o}}\left(-71.78 \mathrm{~kJ} \mathrm{~mol}^{-1}\right)$ indicates a decrease in randomness at the solid/solution interface during the adsorption process of HA on SMZ6.

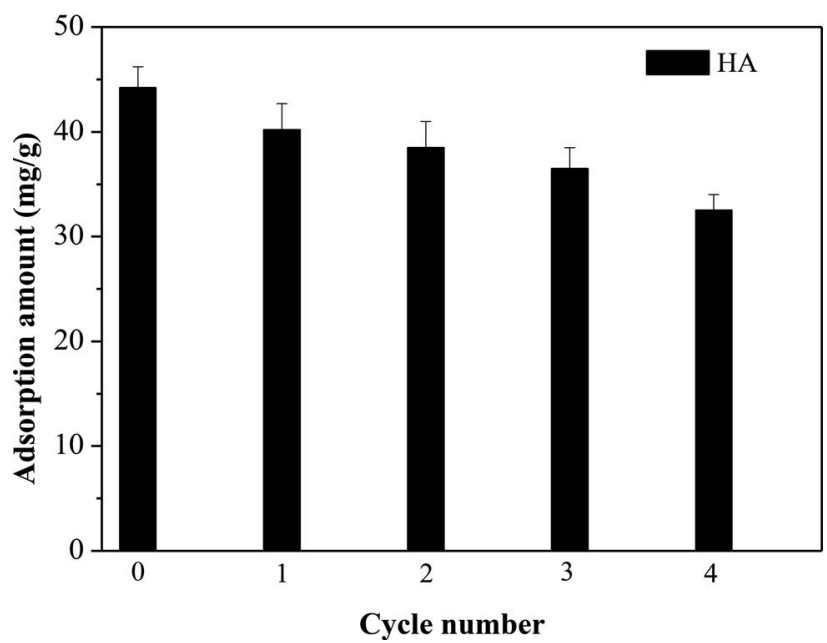

Fig. 10 Amounts of HA adsorbed by SMZ6 after repeated adsorptiondesorption cycles. Experimental conditions: $[\mathrm{HA}]_{0}=40 \mathrm{mg} \mathrm{L}^{-1}$, SMZ6 $=0.8 \mathrm{~g} \mathrm{~L}^{-1}, \mathrm{pH}=6.0, \mathrm{~T}=20^{\circ} \mathrm{C}$.

\subsection{Desorption and regeneration studies}

Desorption studies can contribute to the elucidation of adsorption mechanisms, as well as determining the optimum conditions for recovery of the adsorbent. Two different desorption agents, namely $0.1 \mathrm{M} \mathrm{NaOH}$ and $\mathrm{HCl}$ solutions, were investigated for recovery of HA from the adsorbent. Removal of HA from SMZ6 was favored by high $\mathrm{pH}$, and good desorption efficiency was obtained with $0.1 \mathrm{M} \mathrm{NaOH}$ solution Additionally, the reusability of the adsorbent was tested over four adsorption-desorption cycles (Fig. 10). There was a small progressive decrease in the amount of HA adsorbed after each cycle, but the regenerated adsorbent still possessed about $75 \%$ of its original HA adsorption capacity after four cycles, and thus could be used repeatedly.

\subsection{Column adsorption performance and models}

In addition to the experiments described above, HA adsorption on SMZ6 was also evaluated in fixed bed columns. The effect of bed depth on the breakthrough is shown in Fig. 11 for plots of $C_{t} / C_{0}$ against throughput volume for bed depths of 10 , 20 , and $30 \mathrm{~cm}$. Generally, the breakthrough point is defined as

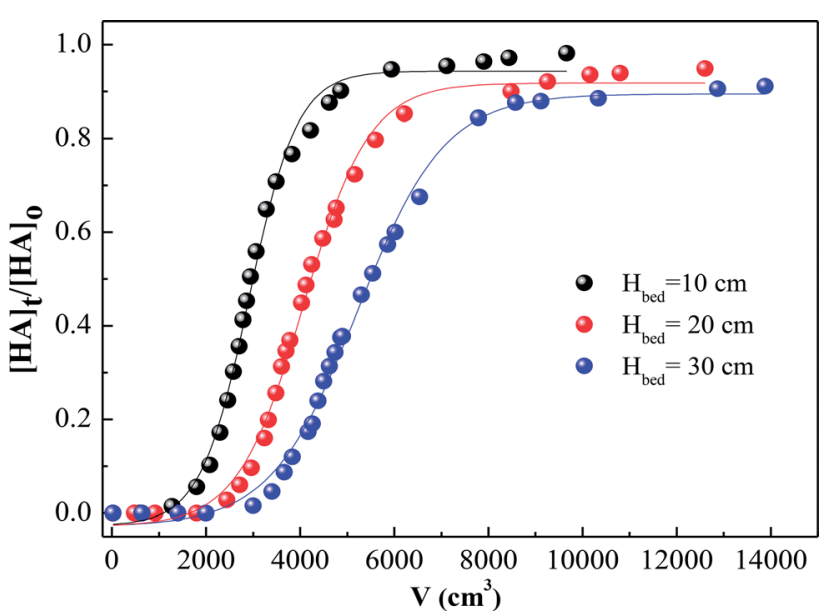

Fig. 11 Breakthrough curves for HA adsorption by SMZ6 fixed columns with different bed depths. Experimental conditions: flow rate $=4.0 \mathrm{~mL} \mathrm{~min}{ }^{-1},[\mathrm{HA}]_{0}=40 \mathrm{mg} \mathrm{L}^{-1}, \mathrm{pH}=6.0, T=20 \pm 1^{\circ} \mathrm{C}$. 


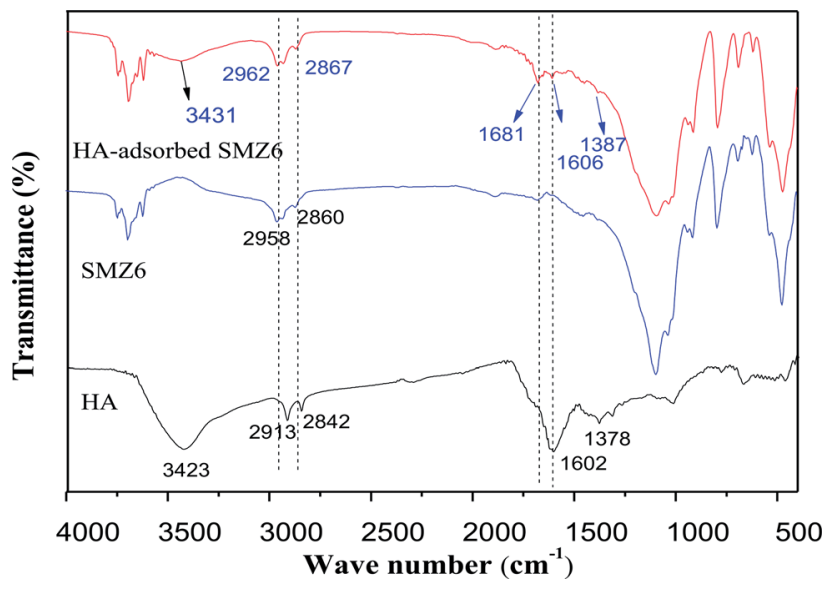

Fig. 12 FTIR spectra of HA, SMZ6 and HA-adsorbed on SMZ6.

the time when the effluent concentration reaches a percentage of the influent concentration $\left(C_{0}\right)$, which is considered unacceptable, e.g. $10 \%\left(C / C_{0}=0: 1\right)$. The results in Fig. 11 indicate that an increase in bed depth increases the breakthrough volume and hence the breakthrough time, and results in longer service time. This is mainly due to the increase in the amount of adsorbent packed in the columns, and consequently the number of binding sites with increasing bed depth. For $C / C_{0}=0.1$, the numbers of bed volumes which passed through the adsorbent were, 300, 560 and $620 \mathrm{BV}$ for 10, 20 and $30 \mathrm{~cm}$, respectively. The Thomas, ${ }^{44}$ Yoon-Nelson, ${ }^{45}$ and Adams-Bohart models ${ }^{46}$ were used to analyze the adsorption behavior of HA in this study. The equations and parameters are listed in Text $\mathrm{S} 1 . \dagger$ The breakthrough behavior for the different bed depths is successfully described by the Thomas model $\left(R^{2}=0.876-0.959\right)$, and the dynamic model parameters are summarized in Table S4. $\dagger$

The bed depth service time (BDST) model based on the theories used for developing the Adams-Bohart model were also used to verify the linear relationship between the bed depth $(Z)$ and saturation time $\left(t_{\mathrm{s}}\right)$ of the column. ${ }^{47}$

$$
t_{\mathrm{s}}=\frac{N_{0}}{C_{0} V} Z-\frac{1}{C_{0} K_{\mathrm{a}}} \ln \left(\frac{C_{0}}{C_{t}}-1\right)
$$

where $K_{\mathrm{a}}$ represents the rate constant in BDST model (min L $\mathrm{mg}^{-1}$ ), and the other parameters have the same meanings as described above. The parameters $N_{0}$ and $K_{\mathrm{a}}$ can be calculated from the slope of the linear plot of $t_{\mathrm{s}}$ versus $Z$ (Fig. S2 $\dagger$ ), which is listed in Table S5. $\dagger$ Values of $N_{0}$ increased and $K_{\mathrm{a}}$ decreased with increasing values of $C_{t} / C_{0}$.

The lines of $t-Z$ at values of $C_{t} / C_{0} 0.1$ and 0.9 are shown in Fig. S2. $\dagger$ Plots of breakthrough times $\left(t_{\mathrm{b}}\right)$ (corresponding to $C_{\mathrm{b}} /$ $C_{0}=0.1$ ) and exhaust times (corresponding to $C_{\mathrm{b}} / C_{0}=0.9$ ) for 10, 20 and $30 \mathrm{~cm}$ bed depths are shown in Fig. S2, $\dagger$ and the BDST constants determined from the slopes and intercepts of these lines are listed in Table S5. $\uparrow$ This figure shows that $t=$ $17.8 Z-689.1$ for $10 \%$ saturation, and $t=91.5 Z-546.9$. With the values of $[\mathrm{HA}] /[\mathrm{HA}]_{0}$ increasing, the values of $N_{0}$ increased while $K_{\mathrm{a}}$ decreased. The BDST model parameters can be helpful to scale up the process for other flow rates without further experimental run.

\subsection{Characterization of adsorbents before and after adsorption of $\mathrm{HA}$}

The FTIR spectra of HA, SMZ6, and HA-adsorbed on SMZ6 are shown in Fig. 12. For HA, the positions of the major absorption bands are: $3423 \mathrm{~cm}^{-1}$ from $\mathrm{H}$-bonded $\mathrm{OH}$ groups, $1647 \mathrm{~cm}^{-1}$ from aromatic $\mathrm{C}=\mathrm{C}$, and $1039 \mathrm{~cm}^{-1}$ from $\mathrm{C}-\mathrm{O}$ stretching. ${ }^{48}$ The FTIR spectra of SMZ6 and HA-adsorbed SMZ6 showed two pronounced characteristic peaks at $2958 \mathrm{~cm}^{-1}$ and $2860 \mathrm{~cm}^{-1}$ that correspond to the stretching vibrations of the $-\mathrm{CH}_{2}$ and $-\mathrm{CH}_{3}$ groups of DAAO. The peak at $3431 \mathrm{~cm}^{-1}$ in the spectrum of HA-adsorbed SMZ6 that is absent from the spectrum of SMZ6 corresponds to $\mathrm{O}-\mathrm{H}$ of the $\mathrm{HA}$, and confirms adsorption of $\mathrm{HA}$ on SMZ6. After HA adsorption, the asymmetric $\mathrm{CH}_{2}$-stretching vibration of DAAO molecules shifted from 2962 to $2958 \mathrm{~cm}^{-1}$ and 2860 to $2867 \mathrm{~cm}^{-1}$, thus indicating interactions of HA molecules with alkyl chains of DAAO.

The XRD spectrum of NZ showed the presence of the zeolites clinoptilolite and mordenite along with quartz, and a similar pattern was observed for SMZ6 (Fig. S3†). After adsorbing HA, the structure of SMZ6 did not changed, although those at 11.31, 20.98, and $25.762 \theta$ were decreased in intensity by HA adsorption, suggesting that the adsorption of HA on SMZ6 was on the adsorbent surface.

The sizes and shapes of particles of NZ, SMZ, and HA-loaded SMZ were investigated by SEM (Fig. 13). NZ contained fibrillar crystals of 10-20 nm diameter and variable lengths. However, after modification with DAAO, the zeolite crystals could not be
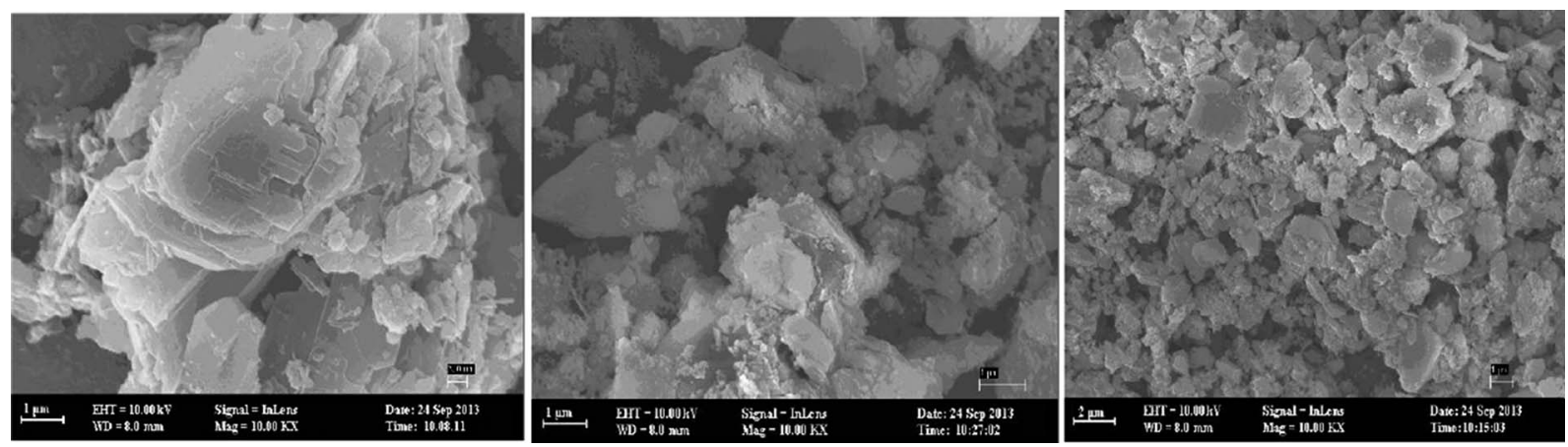

Fig. 13 SEM images of the NZ (a), SMZ6 (b) and HA-SMZ6 (c). 
Hypothetical HA model structure (Buffle's model)

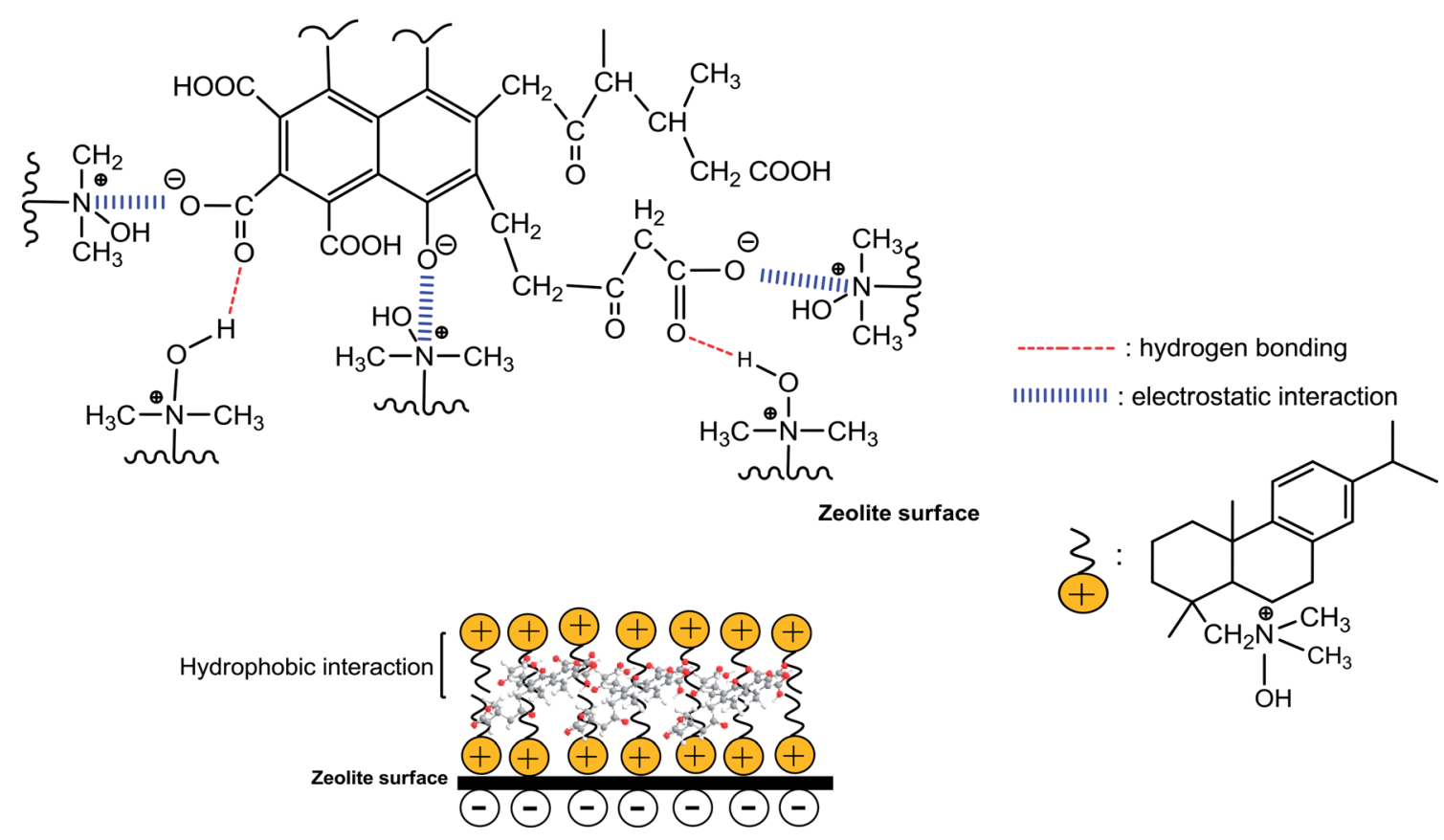

Scheme 1 Schematic of interaction mechanisms between HA and SMZ6.

seen clearly (Fig. 13b), thus confirming that their surfaces were covered with DAAO molecules, and further changes in the surface structure occurred after adsorption of HA on SMZ6 (Fig. 13c). BET measurements showed a large decrease in surface area from $65.71 \mathrm{~m}^{2} \mathrm{~g}^{-1}$ for the NZ to $3.2 \mathrm{~m}^{2} \mathrm{~g}^{-1}$ after modification with DAAO, thus indicating that the surfactant blocked access to the internal pores in the zeolite structure.

\subsection{Proposed adsorption mechanism}

The following mechanisms have been proposed for the adsorption of $\mathrm{HA}^{49-51}$ (i) strong electrostatic interactions between the positively charged outward-pointing head groups of DAAO surfactant bilayers and negatively charged HA molecules in acidic medium; (ii) hydrogen bonding involving the $-\mathrm{N}^{+}\left(\mathrm{CH}_{3}\right)_{2} \rightarrow$ OH groups of the DAAO molecules, which act as hydrogen donors to carboxylate groups in the HA; (iii) hydrophobic interaction between tails of DAAO monolayers and functional groups of HA molecules in alkaline conditions. These various mechanisms are summarized in Scheme 1 . However, mechanism (iii) may be unimportant for adsorption of HA on SMZ6 with DAAO bilayer coverage, since it is removed by $0.1 \mathrm{M} \mathrm{NaOH}$. Futhermore, the results of the present work also suggest an additional mechanism in which the HA molecules are able to slowly diffuse through the DAAO and interact directly with the surface of the zeolite.

\section{Conclusions}

The HA adsorption capacity, of the natural zeolite was greatly enhanced by modification with the novel surfactant DAAO. The amounts of HA adsorbed on SMZ decreased with increasing solution $\mathrm{pH}$, temperature, and ionic strength, but were enhanced by the presence of the cations $\mathrm{Ca}^{2+}$ and $\mathrm{Mg}^{2+}$. The adsorption process obeys pseudo-second order kinetics, and HA adsorption on SMZ6 was best fitted by the Langmuir isotherm model. The dynamic data were well fitted by the Thomas model. It is concluded that the adsorption mechanisms involve mainly hydrogen bonding and electrostatic interactions. HA was efficiently desorbed from loaded SMZ by alkaline solution, and the regenerated adsorbent retained a high affinity for $\mathrm{HA}$ in aqueous solution. Overall this study shows that DAAO modified zeolite can be used as an adsorbent for the removal of HA from aqueous solutions, and can potentially make important contributions to improving drinking water quality by removing HA prior to the disinfection stage.

\section{Conflicts of interest}

There are no conflicts to declare.

\section{Acknowledgements}

This work was financially supported by the National Natural Science Foundation of China (21367004, 21567004, and 21667005), Guangxi Natural Science Foundation (2016GXNSFCA and 2014GXNSFAA118284), the Scientific Research Foundation of Guangxi University for Nationalities (2013MDYB031), and the Young Scholar Innovation Team of Guangxi University for Nationalities (2016). 


\section{References}

1 R. F. Christman, D. L. Norwood, D. S. Millington, J. D. Johnson and A. A. Stevens, Identity and Yields of Major Halogenated Products of Aquatic Fulvic-Acid Chlorination, Environ. Sci. Technol., 1983, 17, 625-628.

2 J. P. Chen and S. Wu, Simultaneous adsorption of copper ions and humic acid onto an activated carbon, J. Colloid Interface Sci., 2004, 280, 334-342.

3 J. N. Wang, Y. Zhou, A. M. Li and L. Xu, Adsorption of humic acid by bi-functional resin JN-10 and the effect of alkali-earth metal ions on the adsorption, J. Hazard. Mater., 2010, 176, 1018-1026.

4 K. J. Wang and B. S Xing, Structural and Sorption Characteristics of Adsorbed Humic Acid on Clay Minerals, J. Environ. Qual., 2004, 34, 342-349.

5 Y. H. Zhan, Z. L. Zhu, J. W. Lin, Y. L. Qiu and J. F. Zhao, Removal of humic acid from aqueous solution by cetylpyridinium bromide modified zeolite, J. Environ. Sci., 2010, 22, 1327-1334.

6 W. L. Yan and R. B. Bai, Adsorption of lead and humic acid on chitosan hydrogel beads, Water Res., 2005, 39, 688-698.

7 C. J. Li, Y. Dong, D. Y. Wu, L. C. Peng and H. N. Kong, Surfactant modified zeolite as adsorbent for removal of humic acid from water, Appl. Clay Sci., 2011, 52, 353-357.

8 J. Lemić, D. Kovačević, M. Tomašević-Čanović, D. Kovačević, T. Stanić and R. Pfend, Removal of atrazine, lindane and diazinone from water by organo-zeolites, Water Res., 2006, 40, 1079-1085.

9 Y. Zeng, H. Woo, G. Lee and J. Park, Adsorption of Cr(VI) on hexadecylpyridinium bromide (HDPB) modified natural zeolites, Microporous Mesoporous Mater., 2010, 130, 83-91.

10 S. C. Bouffard and S. J. B. Duff, Uptake of dehydroabietic acid using organically-tailored zeolites, Water Res., 2000, 34, 2469-2476.

11 Y. E. Benkli, M. F. Can, M. Turan and M. S. Celik, Modification of organo-zeolite surface for the removal of reactive azo dyes in fixed-bed reactors, Water Res., 2005, 39, 487-493.

12 A. Kuleyin, Removal of phenol and 4-chlorophenol by surfactant-modified natural zeolite, J. Hazard. Mater., 2007, 144, 307-315.

13 D. Karadag, E. Akgul, S. Tok, F. Erturk, M. A. Kaya and M. Turan, Basic and reactive dye removal using natural and modified zeolites, J. Chem. Eng. Data, 2007, 52, 24362441.

14 A. Daković, M. Tomašević-Čanović, G. Rottinghaus, V. Dondur and Z. Mašić, Adsorption of ochratoxin A on octadecyldimethyl benzyl ammonium exchangedclinoptilolite-heulandite tuff, Colloids Surf., B, 2003, 30, 157-165.

15 R. S. Boethling, Environmental Fate and Toxicity in Wastewater-Treatment of Quaternary Ammonium Surfactants, Water Res., 1984, 18, 1061-1076.
16 G. Nalecz-Jawecki, E. Grabinska-Sota and P. Narkiewicz, The toxicity of cationic surfactants in four bioassays, Ecotoxicol. Environ. Saf., 2003, 54, 87-91.

17 X. P. Rao, Z. Q. Song and H. Gao, Research and application progress on dehydroabietylamine and its derivatives, Chemistry, 2006, 69, 168-172.

18 V. Agents, Auxiliary Materials, Kirk-Othmer, Encyclopedia of Chemical Technology, Wiley Interscience, NY, 1982.

19 B. Elvers, Ullmann's encyclopedia of industrial chemistry. ed. Stephen Hawkins and William Russey, Verlag Chemie, 1989.

20 S. G. Liu, Y. Q. Ding, P. F. Li, K. S. Diao, X. C. Tan, F. H. Lei, Y. H. Zhan, Q. M. Lib, B. Huang and Z. Y. Huang, Adsorption of the anionic dye Congo red from aqueous solution onto natural zeolites modified with N,N-dimethyl dehydroabietylamine oxide, Chem. Eng. J., 2014, 248, 135144.

21 Y. S. Yeliz and K. Y. Abidin, Suitability of the methylene blue test for surface area, cation exchange capacity and swell potential determination of clayey soils, Eng. Geol., 2008, 102, 38-45.

22 J. Xie, W. Meng, D. Wu, Z. Zhang and H. Kong, Removal of organic pollutants by surfactant modified zeolite: Comparison between ionizable phenolic compounds and non-ionizable organic compounds, J. Hazard. Mater., 2012, 231-232, 57-63.

23 Q. Y. Ding, S. G. Liu, L. Li, Y. B. Ding and K. S. Diao, The Synthesis of N,N-Dimethyl Dehydroabietylamine Oxide and Its Properties, Chem. Ind. For. Prod., 2014, 34, 43-48.

24 J. H. Wang, X. J. Han, H. R. Ma, Y. F. Ji and L. J. Bi, Adsorptive removal of humic acid from aqueous solution on polyaniline/attapulgite composite, Chem. Eng. J., 2011, 173, 171-177.

25 E. M. Murphy, J. M. Zachara and S. C. Smith, Influence of mineralbound humic substances on the sorption of hydrophobic organic compounds, Environ. Sci. Technol., 1990, 24, 1507-1516.

26 A. B. M. Giasuddin, S. R. Kanel and H. Choi, Adsorption of humic acid onto nanoscale zerovalent iron and its effect on arsenic removal, Environ. Sci. Technol., 2007, 41, 20222027.

27 B. A. Goodman, H. L. Green and D. B. McPhail, An electron paramagnetic resonance (EPR) study of the adsorption of copper complexes on montmorillonite and imogolite, Geochim. Cosmochim. Acta, 1984, 48, 2143-2150.

28 S. Lagergren, About the theory of so-called adsorption of soluble substances, K. Sven. vetensk. akad. handl., 1898, 24, 1-39.

29 W. J. Weber and J. C. Morris, Kinetics of adsorption on carbon from solution, J. Environ. Eng. Div., 1963, 89, 31-60.

30 S. H. Maghsoodloo, B. Noroozi, A. K. Haghi and G. A. Sorial, Consequence of chitosan treating on the adsorption of humic acid by granular activated carbon, J. Hazard. Mater., 2011, 191, 380-387.

$31 \mathrm{~J}$. Crank, The mathematics of diffusion, Oxford at the Clarendon Press, London, 1956.

32 A. J. Slaney and R. Bhamidimarri, Adsorption of pentachlorophenol (PCP) by activated carbon in fixed beds: 
Application of homogeneous surface diffusion model, Water Sci. Technol., 1998, 38, 227-235.

33 I. Langmuir, The adsorption of gases on plane surfaces of glass, mica and platinum, J. Am. Chem. Soc., 1918, 40, 1361-1403.

34 H. Freundlich, Concerning adsorption in solutions, J. Phys. Chem., 1906, 57, 385-470.

35 M. J. Temkin and V. Pyzhev, Recent modifications to Langmuir isotherms, Acta Phys.-Chim. Sin., 1940, 12, 217222.

36 D. Doulia, C. Leodopoulos, K. Gimouhopoulos and F. Rigas, Adsorption of humic acid on acid-activated Greek bentonite, J. Colloid Interface Sci., 2009, 340, 131-141.

37 Q. Tao, Z. Y. Xu, J. H. Wang, F. L. Liu, H. Q. Wan and S. R. Zheng, Adsorption of humic acid to aminopropyl functionalized SBA-15, Microporous Mesoporous Mater., 2010, 131, 177-185.

38 W. S. W. Ngah, M. A. K. M. Hanafiah and S. S. Yong, Adsorption of humic acid from aqueous solutions on crosslinked chitosan-epichlorohydrin beads: kinetics and isotherm studies, Colloids Surf., B, 2008, 65, 18-24.

39 C. J. Li, Y. Dong, D. Y. Wu, L. C. Peng and H. A. Kong, Surfactant modified zeolite as adsorbent for removal of humic acid from water, Appl. Clay Sci., 2011, 52, 353-357.

40 Y. L. Tang, S. Liang, S. L. Yu, N. Y. Gao, J. Zhang, H. C. Guo and Y. L. Wang, Enhanced adsorption of humic acid on amine functionalized magnetic mesoporous composite microspheres, Colloids Surf., A, 2012, 406, 61-67.

41 M. S. Gasser, H. T. Mohsen and H. F. Aly, Humic acid adsorption onto $\mathrm{Mg} / \mathrm{Fe}$ layered double hydroxide, Colloids Surf., A, 2008, 331, 195-201.
42 F. Arias and T. K. Sen, Removal of zinc metal ion $\left(\mathrm{Zn}^{2+}\right)$ from its aqueous solution by kaolin clay mineral: A kinetic and equilibrium study, Colloids Surf., A, 2009, 348, 100-108.

43 Q. S. Liu, T. Zheng, P. Wang, J. P. Jiang and N. Li, Adsorption isotherm, kinetic and mechanism studies of some substituted phenols on activated carbon fibers, Chem. Eng. J., 2010, 157, 348-356.

$44 \mathrm{H}$. C. Thomas, Heterogeneous ion exchange in a flowing system, J. Am. Chem. Soc., 1944, 66, 1664-1666.

45 Y. H. Yoon and J. H. Nelson, Application of gas adsorption kinetics-II. A theoretical model for respirator cartridge service life and its practical applications, Am. Ind. Hyg. Assoc. J., 1984, 45, 517-524.

46 G. S. Bohart and E. Q. Adams, Some aspects of the behavior of charcoal with respect to chlorine, J. Am. Chem. Soc., 1920, 42, 523-544.

47 S. G. Wang, W. X. Gong, X. W. Liu, B. Y. Gao and Q. Y. Yue, Removal of fulvic acids using the surfactant modified zeolite in a fixed-bed reactor, Sep. Purif. Technol., 2006, 51, 367-373.

48 P. Huttenloch, K. E. Roehl and K. Czurda, Sorption of nonpolar aromatic contaminants by chlorosilane surface modified natural minerals, Environ. Sci. Technol., 2001, 35, 4260-4264.

49 D. Doulia, C. Leodopoulos, K. Gimouhopoulos and F. Rigas, Adsorption of humic acid on acid-activated Greek bentonite, J. Colloid Interface Sci., 2009, 340, 131-141.

50 L. P. Weng, W. H. Van Riemsdijk and T. Hiemstra, Adsorption of humic acids onto goethite: Effects of molar mass, pH and ionic strength, J. Colloid Interface Sci., 2007, 314, 107-118.

51 J. A. E. Buffle, Les substances humiques et leurs interactions avec les ions mineraux, Proc. Commission d'hydrologie appliquee de AGHTM l'Universite d'Orsay, 1977, pp. 3-10. 